\title{
Factors predicting success of vaginal delivery in women with oligohydramnios undergoing induction of labour
}

\author{
Ritika Malviya $^{1 *}$, Suman Mahor', Sarada Saranu² \\ ${ }^{1}$ Department of Obstretics and Gynaecology, Gandhi Medical College Bhopal, Madhya Pradesh, India \\ ${ }^{2}$ Department of Obstretics and Gynaecology, Kamineni Hospital Hyderabad, Telangana, India
}

Received: 15 January 2021

Revised: 15 February 2021

Accepted: 16 February 2021

\author{
*Correspondence: \\ Dr. Ritika Malviya, \\ E-mail: ritika_medico@yahoo.in
}

Copyright: (c) the author(s), publisher and licensee Medip Academy. This is an open-access article distributed under the terms of the Creative Commons Attribution Non-Commercial License, which permits unrestricted non-commercial use, distribution, and reproduction in any medium, provided the original work is properly cited.

\begin{abstract}
Background: Aim was to study the predicting factors for success of vaginal delivery, in women with oligohydramnios undergoing induction of labour.

Methods: An observational study conducted in tertiary care centre Kamineni Hospital in 100 patients in 1-year duration with vaginal misoprostol tablets to predict the success of vaginal delivery in cases, if oligohydramnios undergoing induction of labor.

Results: In our study total 100 cases was induced. Among these $81 \%$ had successful normal vaginal delivery and $19 \%$ had caesarean section delivery. Those who underwent caesarean section, their NST had become non reassuring at any time in labour, provided all supportive measures but their labour was terminated by caesarean section for sake of mother or baby.

Conclusions: It is preferable to induce the patients of oligohydramnios at term with continous fetal heart rate monitoring and also variability of the fetal heart rate pattern with uterine contractions.
\end{abstract}

Keywords: Oligohydramnios, Amniotic fluid index, Induction, Misoprostol

\section{INTRODUCTION}

Amniotic fluid is a part of the baby life support system during labour. ${ }^{1}$ It acts as a medium through which baby slips out of the birth canal, so certain amount of the fluid will always be needed to get this effect. Another important mechanical function of amniotic fluid is to provide an adequate cushion for the umbilical cord so to prevent the undue contractions of umblical cord. As the cord compression leads to fetal heart rate decelerations in NST which requires more operative interferences. Nature has made floating bed in form of amniotic fluid filled cavity with liquor amnii for the requirement of fetus, for its existence and growth in sterile environment, its antibacterial properties, regulation of temperature, avoidance of external injury and reduction in impact of uterine contractions. ${ }^{2,3}$ Thus, it is required to evaluate the amniotic fluid volume during assessment of fetal status whether as a part of antenatal testing protocol or in the labour suite clinically. AFI $5-8 \mathrm{~cm}$ is considered as borderline oligohydramnios and AFI less than $5 \mathrm{~cm}$ is oligohydramnios. Oligohydramnios occurs in $1-5 \%$ of pregnancies at term. ${ }^{5,6}$ Oligohydramnios is associated with maternal morbidity in the form of increased rates of induction and operative interference and further rate of elective caesarean deliveries. Early detection of oligohydramnios and its management may help in decreased caesarean deliveries and also reducing of perinatal morbidity and mortality. ${ }^{7}$ Obstreticians have increasingly resorted to induction of labour in pregnancy complicated by decreased amniotic fluid volume so as to get more vaginal deliveries. Hence we are planning for a study to know the perinatal outcome in cases of induction in oligohydramnios. The present study was designed to 
study the outcome of pregnancies with $\mathrm{AFI}<8 \mathrm{~cm}$ at 37 weeks of gestation.

\section{METHODS}

The aim of the study is the Prospective Evaluation of outcome of labour induction in oligohydramnios.

The study, an institution based prospective observational study, was conducted at Kamineni Hospital L. B. Nagar, among 100 women presented with oligohydramnois during one year period from1st June 2017 and 30th May 2018 with fulfilment of inclusion criteria and were enrolled after obtaining an informed consent, Other potential explanatory variables has been obtained including maternal age, booking status, Pregnancy induced hypertension, hypothyrodism, GDM and others risk factors at the time of admission and institutional ethical clearance.

\section{Inclusion criteria}

Inclusion criteria were 1) booked and un-booked cases of gestational age 37 weeks and above 2) women with any order of parity 3) singleton pregnancy cephalic presentation 4) $\mathrm{AFI}<8 \mathrm{~cm}$ at term gestation.

\section{Exclusion criteria}

Exclusion criteria were 1) women with gestational age $<37$ weeks 2) multiple pregnancies 3) women with AFI $>8 \mathrm{~cm}$ at term gestation 4) women presenting with premature rupture of membranes 5) congenital anomalies.

\section{Statistical analysis}

Categorical variables will be presented in number and percentage (\%) and continuous variables will be presented as mean \pm SD and median. Normality of data will be tested by Kolmogorov-Smirnov test.

\section{Inferential statistic}

Statistical tests will be applied as follows- 1) quantitative variables will be compared using Unpaired t-test/MannWhitney Test (when the data sets were not normally distributed) between the primi and multi parity 2) qualitative variables will be compared using Chi-Square test /Fisher's exact test.
A $p$ value of $<0.05$ will be considered statistically significant. Results would be analysed and expressed as percentages.

\section{Methodology}

AFI was measured measured using Phelan's four quadrant ultrasound technique at admission. ${ }^{4}$ Assessment of Bishops score was done to determine favorability for induction. Induction methods was sweeping of membranes and Vaginal misoprostol tablets $25 \mathrm{mcg}$. Augmenting agent was injection oxytocin. Vaginal misoprostol tablets to be repeated every 4th hourly, maximum upto 6 doses till they into active labour. Once active labour reached rupture of membranes was done. Augmentation of labour was done with inj oxytocin Doses of injection Syntocinon for augmentation of labour was used; inj syntocinon 5 units in cases of primigravida and 2.5 units in multigravida respectively and titration was done accordingly. Progress of labour monitoring was done with CTG (cardiotocography). Intermittent as well as extended when required.

CTG was done for all patients. Those who developed significant variable, repetitive late decelerations or other ominous FHR pattern with or without meconium stained liquor which persisted inspite of corrective measures like change in maternal position to left lateral position, hydration with intravenous fluids, oxygen inhalation and stopping oxytocin were diagnosed as fetal distress and delivered by instrumental vaginal delivery or Emergency caesarean section. Amnioinfusion was not done in our study. All newborns were attended be paediatricians. Various outcome measures were recorded: induced labour, nature of amniotic fluid, FHR tracings, mode of delivery and indication for caesarean section or instrumental vaginal delivery, Apgar score at one minute and five minutes, birth weight, admission to neonatal ward, perinatal morbidity and mortality.

\section{RESULTS}

A total number of 100 antenatal women with term pregnancies who underwent both clinical and ultrasonographic assessment for amount of liquor were recruited. Various factors were studied and compared in study population. All cases underwent induction of labour in view of oligohydramnios and were monitored. The results were recorded and tabulated. The outcomes were statistically analyzed using parameters like standard deviation, chi square test, pearson coefficient and $\mathrm{Z}$ test.

Table 1: Number of primi and multi gravida's.

\begin{tabular}{|llll|}
\hline Gravida & Number & Unbooked cases & Cesarean Delivery in unbooked cases \\
\hline Primigravida & 68 & 12 & 02 \\
\hline Multigravida & 32 & 4 & 00 \\
\hline Total & 100 & 14 & 02 \\
\hline
\end{tabular}


In our study total primigravidas cases were $68 \%$ and multigravidas' cases were $32 \%$. $17.64 \%$ and $12.5 \%$ case were unbooked, respectively in primi and multi gravida. Only 2 among unbooked cases were delivered by caesarean section in our study. $81 \%$ cases had Amniotic fluid index between 4-6 in our study.

Table 2: Period of gestation.

\begin{tabular}{|llll|}
\hline $\begin{array}{l}\text { Gestational } \\
\text { age (weeks) }\end{array}$ & $\begin{array}{l}\text { No of } \\
\text { patients }\end{array}$ & $\begin{array}{l}\text { Vaginal } \\
\text { delivery }\end{array}$ & $\begin{array}{l}\text { Caesarean } \\
\text { delivery }\end{array}$ \\
\hline $\mathbf{3 7 - 3 8}$ & 48 & 39 & 09 \\
\hline $\mathbf{3 8 - 3 9}$ & 30 & 25 & 05 \\
\hline $\mathbf{3 9 - 4 1}$ & 22 & 17 & 05 \\
\hline Total & 100 & 81 & 19 \\
\hline
\end{tabular}

Maximum patients were with gestational age 37 to 38 weeks. $22 \%$ was with 39 to 41 weeks of gestation.

Table 3: Amniotic fluid index.

\begin{tabular}{|lllc|}
\hline $\begin{array}{l}\text { AFI in } \\
\text { cms }\end{array}$ & $\begin{array}{l}\text { No of } \\
\text { patients }\end{array}$ & $\begin{array}{c}\text { Vaginal } \\
\text { delivery }\end{array}$ & $\begin{array}{c}\text { Caesarean } \\
\text { delivery }\end{array}$ \\
\hline $\mathbf{0 - 3}$ & 08 & 07 & 01 \\
\hline $\mathbf{4 - 6}$ & 81 & 63 & 18 \\
\hline$>\mathbf{6}$ & 11 & 11 & 00 \\
\hline Total & 100 & 81 & 19 \\
\hline
\end{tabular}

Table 4: Bishop's score.

\begin{tabular}{|llll|}
\hline $\begin{array}{l}\text { Bishops } \\
\text { score }\end{array}$ & $\begin{array}{l}\text { No. of } \\
\text { patients }\end{array}$ & $\begin{array}{l}\text { Vaginal } \\
\text { delivery }\end{array}$ & $\begin{array}{l}\text { Caesarean } \\
\text { delivery }\end{array}$ \\
\hline $\mathbf{6}$ & 03 & 01 & 02 \\
\hline $\mathbf{7}$ & 26 & 22 & 04 \\
\hline $\mathbf{8}$ & 48 & 43 & 05 \\
\hline $\mathbf{9}$ & 23 & 15 & 08 \\
\hline Total & 100 & 81 & 19 \\
\hline
\end{tabular}

Table 5: The mean value for Bishops score of the patients was 8.08 and standard deviation was 0.8 .

\begin{tabular}{|l|lll|}
\hline & $\begin{array}{l}\text { No. of } \\
\text { patients }\end{array}$ & Mean & $\begin{array}{l}\text { Standard } \\
\text { deviation }\end{array}$ \\
\hline Bishops score & 100 & 8.08 & 0.8 \\
\hline
\end{tabular}

Maximum number of patients, $48 \%$ had bishops score of $8,23 \%$ had bishops score of 9 . The lowest bishops score in our study was 6 . The highest bishops score in our study was $916 \%$ patients had meconium-stained liquor when rupture of membranes was done.

A total 8 patients had thick meconium-stained liquor and 4 of them delivered with caesarean section. 1 patient had moderate meconium-stained liquor and was delivered with caesarean section. 9 patients had thin meconiumstained liquor and 1 of them delivered with caesarean section.
A total $81 \%$ delivered by vaginal delivery and $19 \%$ delivered by caesarean section being induced with misoprostol, in their case labour terminated by caesarean section. $19 \%$ patients show non-reassuring NST. Among these six patients shows meconium-stained liquor grade 3.

A total $19 \%$ cases showed non reassuring NST in their intrapartum period, which may be due to use of misoprostol for induction or hyperstimulation of uterus which lead to this effect or syntocinon augmentation.

Table 6: Misoprostrol dose distribution

\begin{tabular}{|llll|}
\hline \multirow{2}{*}{$\begin{array}{l}\text { Dose } \\
\text { needed }\end{array}$} & $\begin{array}{l}\text { Mode of delivery } \\
\text { Vaginal }\end{array}$ & $\begin{array}{l}\text { Caesarean } \\
\text { N }(\%)\end{array}$ & Total \\
\hline Single & $16(19.75)$ & $2(10.53)$ & $18(18)$ \\
\hline Two & $22(27.16)$ & $13(68.42)$ & $35(35)$ \\
\hline $\begin{array}{l}\text { Three or } \\
\text { more }\end{array}$ & $43(53.09)$ & $4(21.05)$ & $47(47)$ \\
\hline Total & $81(100)$ & $19(100)$ & $100(100)$ \\
\hline
\end{tabular}

*Pearson $\operatorname{chi}^{2}(2)=11.5739, \operatorname{Pr}=0.003$

Table 7: Mode of delivery as per NST.

\begin{tabular}{|c|c|c|c|}
\hline \multirow[b]{2}{*}{ NST } & \multicolumn{2}{|c|}{ Mode of delivery } & \multirow[b]{2}{*}{ Total } \\
\hline & $\begin{array}{l}\text { Vaginal } \\
\mathbf{N}(\%)\end{array}$ & $\begin{array}{l}\text { Caesarean } \\
\mathbf{N}(\%)\end{array}$ & \\
\hline Reactive & $81(100)$ & $0(00)$ & $81(81)$ \\
\hline Non-assuring & $0(00)$ & $19(100)$ & $19(19)$ \\
\hline Total & $81(100)$ & $19(100)$ & $100(100)$ \\
\hline
\end{tabular}

*Pearson $\operatorname{chi}^{2}(1)=100.0000, \operatorname{Pr}=0.000$

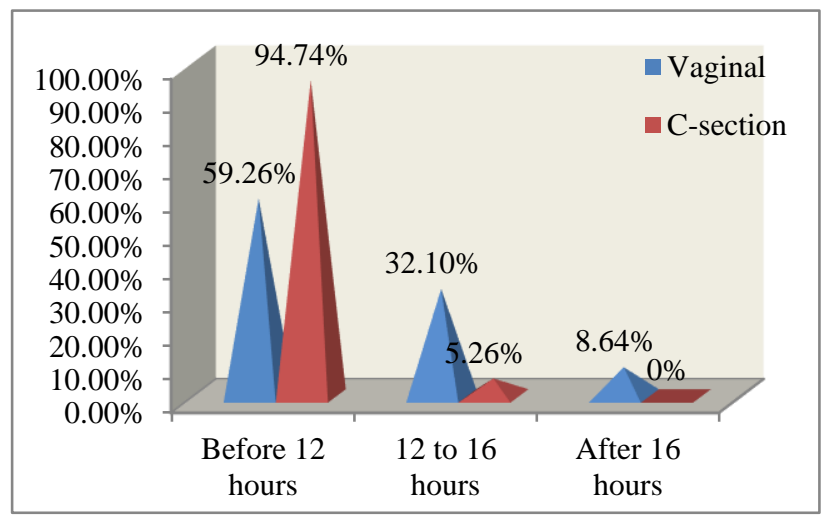

Figure 1: Induction and delivery interval in study population.

Table 8: Meconium stained liqour.

\begin{tabular}{|llll|}
\hline MSL & $\begin{array}{l}\text { No of } \\
\text { patients }\end{array}$ & $\begin{array}{l}\text { Vaginal } \\
\text { delivery }\end{array}$ & $\begin{array}{l}\text { Caesarean } \\
\text { delivery }\end{array}$ \\
\hline Grade 1 & 09 & 08 & 01 \\
\hline Grade II & 01 & 00 & 01 \\
\hline Grade III & 06 & 02 & 04 \\
\hline Total & 16 & 10 & 06 \\
\hline
\end{tabular}




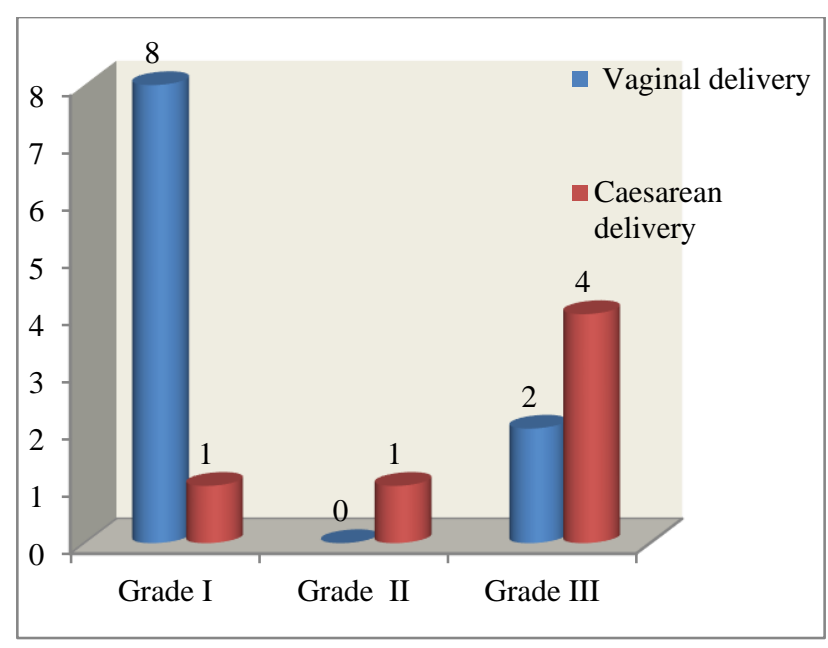

Figure 2: Cases who develop meconium-stained liquor during process of induction.

A total $66 \%$ was delivered within 12 hours of induction, $27 \%$ delivered within 16 hours and and only $7 \%$ delivered after the duration of 16 hours.

Table 9: Time interval.

\begin{tabular}{|c|c|c|c|c|c|}
\hline \multicolumn{2}{|c|}{$\begin{array}{l}\text { Induction to } \\
\text { delivery } \\
\text { interval }\end{array}$} & Vaginal & $\begin{array}{l}\text { C- } \\
\text { section }\end{array}$ & Total & P value \\
\hline \multirow{2}{*}{$\begin{array}{l}\text { Before } \\
12 \text { hours }\end{array}$} & $\mathrm{N}$ & 48 & 18 & 66 & \multirow{8}{*}{0.013} \\
\hline & $\%$ & 59.26 & 94.74 & 66.00 & \\
\hline \multirow{2}{*}{$\begin{array}{l}12 \text { to } 16 \\
\text { hours }\end{array}$} & $\mathrm{N}$ & 26 & 1 & 27 & \\
\hline & $\%$ & 32.10 & 5.26 & 27.00 & \\
\hline \multirow{2}{*}{$\begin{array}{l}\text { After } 16 \\
\text { hours }\end{array}$} & $\mathrm{N}$ & 7 & 0 & 7 & \\
\hline & $\%$ & 8.64 & 0.00 & 7.00 & \\
\hline \multirow{2}{*}{ Total } & $\mathrm{N}$ & 81 & 19 & 100 & \\
\hline & $\%$ & 100 & 100 & 100 & \\
\hline
\end{tabular}

Total neonatal admissions to neonatal intensive care unit were $15 \%$, out of which $86 \%$ cases was delivered vaginally and $13 \%$ cases were delivered by caesarean section.
Table 10: Neonatal outcome.

\begin{tabular}{|c|c|c|c|c|c|}
\hline $\begin{array}{l}\text { NICU } \\
\text { admissic }\end{array}$ & & Vaginal & $\begin{array}{l}\text { C- } \\
\text { section }\end{array}$ & Total & $P$ value \\
\hline \multirow{2}{*}{ Absent } & $\mathrm{N}$ & 68 & 17 & 85 & \multirow{6}{*}{0.544} \\
\hline & $\%$ & 83.95 & 89.47 & 85.00 & \\
\hline \multirow{2}{*}{ Present } & $\mathrm{N}$ & 13 & 2 & 15 & \\
\hline & $\%$ & 16.05 & 10.53 & 15.00 & \\
\hline \multirow{2}{*}{ Total } & $\mathrm{N}$ & 81 & 19 & 100 & \\
\hline & $\%$ & 100 & 100 & 100 & \\
\hline
\end{tabular}

Considering BMI of patient, standard deviation was 2.74 with mean 23.37 with a minimum value 18 and maximum value 32 . Bishops score with minimum score of 7 and maximum with 10 , mean value of 8.08 and standard deviation of 0.8. Comparison of Apgar score of newborns at 1 and 5 minutes respectively with mean and standard deviations. Doses of misoprostol needed with minimum of 1 dose and maximum with 7 doses, mean of 2.75 and standard deviation of 1.38 .

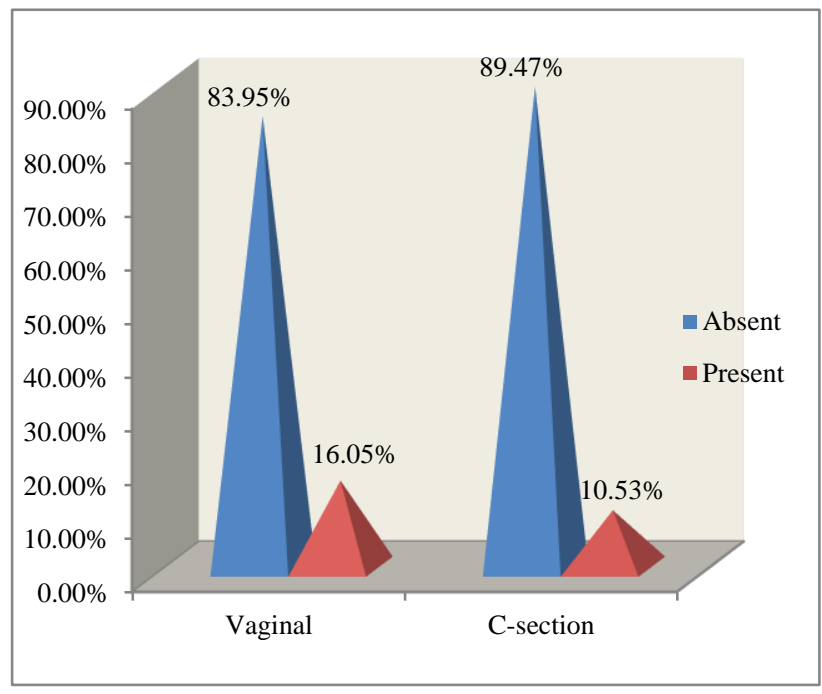

Figure 3: Percentage of neonatal care admission in vaginal and cesarean deliveries.

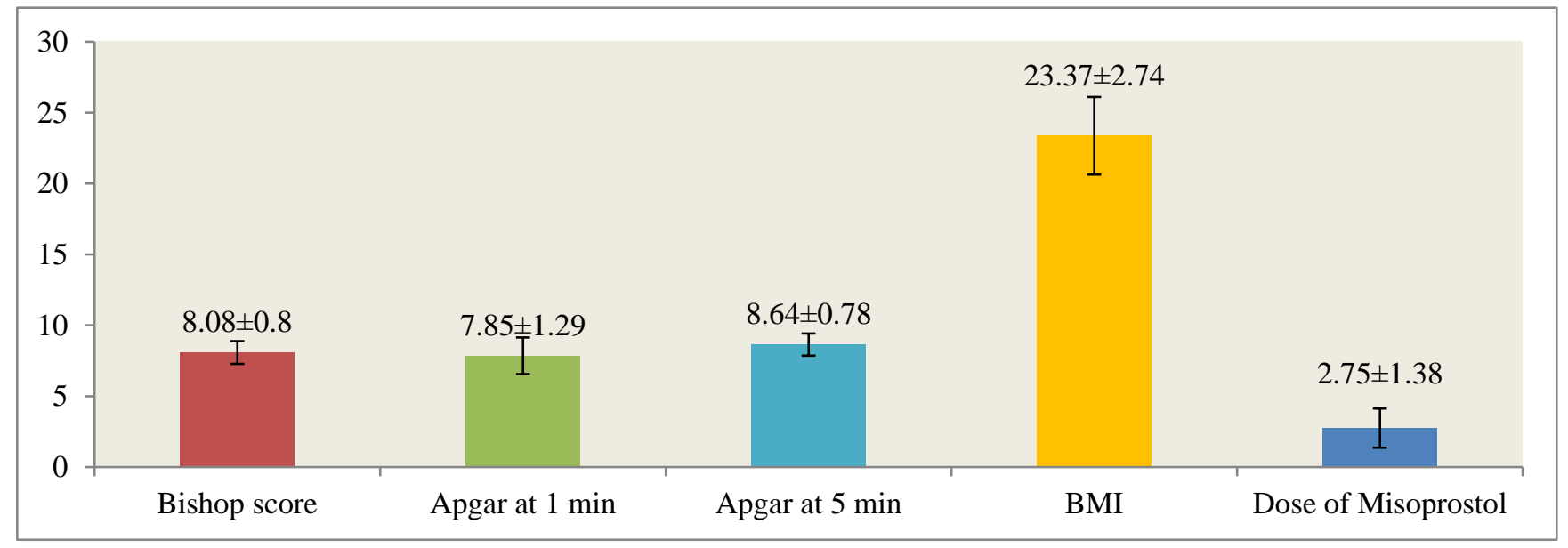

Figure 4: Graphical presentation of bishop score, Apgar score, BMI, Misoprostol. 
Table 11: Mean, standard deviation for bishop score, Apgar score, BMI, Misoprostol.

\begin{tabular}{|llllll|}
\hline Variable & No of observations & Mean & Standard deviation & Minimum & Maximum \\
\hline Bishop score & 100 & 8.08 & 0.8 & 7 & 10 \\
\hline Apgar at 1 min & 100 & 7.85 & 1.29 & 1 & 9 \\
\hline Apgar at 5 min & 100 & 8.64 & 0.78 & 3 & 10 \\
\hline BMI & 100 & 23.37 & 2.74 & 18 & 32 \\
\hline Dose of Misoprostol & 100 & 2.75 & 1.38 & 1 & 7 \\
\hline
\end{tabular}

\section{DISCUSSION}

Accurate antepartum estimation of amniotic fluid volume by clinical methods alone is difficult but it is easily diagnosed by ultrasound methods. With the easier availability of the ultrasound nowadays more cases of oligohydramnios are being identified. This helps us to be more cautious and anticipate problems especially during labour. Among the 100 induced patients for oligohydramnios, 81 delivered normally with full monitoring of labour by every 4th hourly repeat NST, need for misoprostol, followed by augmentation of labour with injection oxytocin. Patients who shows NST non reasuring during monitoring in labour were given supportive measures like left lateral position, oxygen inhalation, intravenous hydration and managed further accordingly. Considering uterine action in cardiotomography, in case of hyperstimulation and moderately active uterus, further doses of misoprostol deferred in view of same and if needed induction started again once contraction passed away without affecting the reactive pattern of NST.

In this study, out of the 100 subjects who underwent caesarean section, 19 had non reassuring pattern either antepartum or during labor. The possibility that oligohydramnios may be associated with umbilical cord compression and resultant fetal distress in presence of uterine contractions is usually the driving factor in opting for caesarean section by obstetricians. There is a significant divergence regarding the management of isolated oligohydroamnios. Despite being unsure of its benefit, most practioners lean towards intervention. There was no difference between groups in neonatal outcome or perinatal morbidity or mortality. In our study, the caesarean section rate was approximately $20 \%$ after the labour induction. In a case-control study by Conway in 1998. ${ }^{10} 183$ low-risk, term parturients with oligohydramnios were matched with 183 women of similar gestational age and parity who presented in spontaneous labour. The patients with oligohydramnios were induced and showed an increased caesarean delivery rate. It was not due to non-reassuring fetal surveillance and was attributed to induction process. A study of Norwich published in 20079, induction of labour and caesarean section was high but there was no increased perinatal morbidity when compared with pregnancies managed expectantly. There have been other studies with similar results which shows the correlation. ${ }^{11,12}$

\section{CONCLUSION}

No appropriate route of delivery can be recommended in cases of oligohydramnios. It is preferable to induce the patients of oligohydramnios at term with continous fetal heart rate monitoring and also variability of the fetal heart rate pattern with uterine contractions. Termination of pregnancy with oligohydramnios by caesarean delivery or instrumental delivery should be done when fetal distress does not improve with supportive measures. Antepartum diagnosis of oligohydramnios warrants close fetal surveillance during intrapartum period to avoid unnecessary intervention.

\section{Recommendations}

We recommend that large scale, multicentric studies should be performed in Indian population which will help to resolve the controversy of labour induction in cases of oligohydramnios at term considering both maternal and fetal indications.

Funding: No funding sources Conflict of interest: None declared

Ethical approval: The study was approved by the Institutional Ethics Committee

\section{REFERENCES}

1. Ali HS. Assessment of amniotic fluid index in normal pregnancy at a tertiary care Hospita setting. Ziauddin university, Karachi Pakistan. J ayub Med Coll Abbotabad. 2009;21(3);149-50

2. Dasari P, Niveditta G, Raghavan S. The maximal vertical pocket and amniotic fluid index in predicting fetal distress in prolonged pregnancy. Int J Gynaecol Obstet. 2007;969(2):89-93.

3. Brace RA. Physiology of amniotic fluid volume regulation. Clin Obstet Gynecol. 1997;40(2)280-9.

4. Ott WJ. Reevaluation of the relationship between amniotic fluid volume and perinatal outcome. Am J Obstet Gynecol 2005;192:1803-9.

5. Moore TR. Clinical assessment of amniotic fluid. Clin Obstet Gynecol 1997;40(2):303-13.

6. Conway DL, Adkins WB, Shroedere B. Isolated oligohydramnios in a term Pregnancy: Is it a clinical entity. J Matern Fetal Med 1998;7:197-200 
7. Elsendabesee D. Majumdar S, Sinha S. obstretician attitude towards isolated oligohydramnios at term. J Obstet Gynecol 2007:27(6):574-6.

8. Ahmed H, Munim S. Isolated oligohydroamnios is not an indicator for adverse Perinatal outcome. $\mathrm{J}$ de Mathématiques Pures et Appliquées. 2009;59:691

9. Anis F, Haseena J, Ramadoss R,Sekaran M, Radhika $\mathrm{S}$. Isolated oligohydramnios is an indication of labour? Int J sci Stud. 2014;2(9):32-5

10. Sowmya K, Varghese B, Borkar Y U. Effect of isolated oligohydramnios in Otherwise normal term pregnancy. Int J Busin Res. 2014;05(2):98-101
11. Kahkhaie KR, Keikha F, Keikhaie KR, et al. Perinatal Outcome After Diagnosis of Oligohydramnios at Term. Iran red Crescent Med J. 2014;16(5):e11772

12. Bachchav AA, Waikar M. Low Amniotic Fluid Index at Term as a Predictor of Adverse Perinatal Outcome. J Obstet Gynecol India. 2014;64(2):120-3.

Cite this article as: Malviya R, Mahor S, Saranu S. Factors predicting success of vaginal delivery in women with oligohydramnios undergoing induction of labour. Int J Reprod Contracept Obstet Gynecol 2021;10:1491-6. 